\title{
Gêneros acadêmicos em cursos de especialização: conjunto ou colônia de gêneros? ${ }^{1}$
}

\section{Academic genres in graduate courses: genre sets or colonies?}

Benedito Gomes Bezerra*

Universidade de Pernambuco

Garanhuns - Pernambuco / Brasil

RESUMO: Neste trabalho, investiga-se a inter-relação entre os gêneros acadêmicos produzidos/lidos pelos estudantes em um curso de especialização em língua portuguesa, procurando-se determinar em que medida os conceitos de conjunto e colônia de gêneros são aplicáveis para descrever consistentemente a totalidade desses gêneros. A metodologia incluiu, além de um questionário aplicado aos alunos, a análise de um corpus representativo dos gêneros acadêmicos mais frequentemente lidos/produzidos pelos alunos, incluindo-se artigos científicos, resumos, resenhas, projetos de pesquisa e monografias de conclusão de curso. Os resultados apontam para pontos de interseç̧ão, bem como para diferenças entre os conceitos, quando aplicados aos gêneros sob estudo, o que sugere que podem ser utilizados de forma complementar ou isolada, dependendo dos objetivos a que se propõe a análise.

PALAVRAS-CHAVE: Gêneros acadêmicos; conjunto de gêneros; colônia de gêneros.

ABSTRACT: This work investigates the interrelationship among the academic genres produced/read by students in a graduate course in Portuguese language, seeking to determine to what extent the concepts of genre sets and genre colonies can be consistently applied to describe these genres as a whole. The methodology included, in addition to a questionnaire administered to students, the analysis of a representative corpus of the academic genres most often read/produced by the students, including research articles, summaries, book reviews, research projects and final papers. The results indicate points of intersection as well as differences between the concepts, when applied to the genres under study, which suggests that they can be used alone or complementarily, depending on the aims that are proposed for the analysis.

KEYWORDS: Academic genres; genre sets; genre colonies.

${ }^{1}$ Este trabalho contou com o apoio financeiro do CNPq, Processo 471957/2010-0.

* beneditobezerra@yahoo.com.br 


\section{Considerações iniciais}

Embora uma parte expressiva das pesquisas em análise de gêneros textuais frequentemente se concentre no estudo de gêneros específicos, tomados isoladamente, nos últimos tempos têm surgido propostas teóricometodológicas para a abordagem dos gêneros de uma forma mais realista, em inter-relação dinâmica uns com os outros, tal como se apresentam nos distintos domínios discursivos. Tais propostas, a exemplo dos conceitos de conjunto de gêneros (BAZERMAN, 2005²) e colônia de gêneros (BHATIA, 2004), discutidos adiante neste trabalho, mostram-se produtivas para evidenciar a complexidade das trocas linguísticas e discursivas mediadas pelos gêneros.

Em diversas situações de interação social, como é o caso do contexto acadêmico de cursos de graduação e de pós-graduação, os estudantes travam contato com diversos gêneros acadêmicos, em função de atividades de leitura e de produção de textos. Situados em uma instância específica de atividade social, esses gêneros necessariamente se constituem e se apresentam numa relação recíproca, por vezes configurando-se como redes complexas que refletem um esperado processo de letramento acadêmico por parte do aluno.

Diante disso, o objetivo deste trabalho é investigar a inter-relação entre os diversos gêneros produzidos ou lidos por estudantes de um curso de pósgraduação lato sensu, em decorrência das exigências acadêmicas do curso, procurando-se determinar em que medida os conceitos de conjunto de gêneros e colônia de gêneros são aplicáveis para descrever a totalidade desses gêneros de maneira heuristicamente consistente.

Para responder às indagaçōes que guiaram a pesquisa, foram aplicados questionários a alunos de um curso de especialização em ensino de Língua Portuguesa oriundos de três turmas localizadas em diferentes cidades do interior pernambucano. O curso foi oferecido por uma universidade pública do estado de Pernambuco e os alunos eram em sua maioria professores da rede estadual e recém-egressos do curso de Letras. Para este estudo, levaremos em consideração uma amostra de quinze questionários, subdivididos em quantidades iguais por cada turma. No questionário, interessam-nos particularmente as informaçôes e a percepção dos alunos sobre as atividades de leitura e escrita desenvolvidas no decorrer do curso, bem como os gêneros textuais envolvidos.

\footnotetext{
${ }^{2} \mathrm{O}$ texto original, "Speech Acts, Genres, and Activity Systems: How Texts Organize Activity and People", é de 2004. Neste artigo, utilizarei a tradução para o português de Judith Hoffnagel e Ana Regina Vieira, publicada em 2005.
} 
A investigação dos gêneros produzidos e recebidos pelos alunos a partir da percepção e informação dos próprios alunos constitui procedimento metodológico bem estabelecido na análise de gêneros. Por exemplo, enquanto Vijay K. Bhatia (1993) sugere que o analista cheque suas descobertas com um informante no próprio ambiente da pesquisa, Charles Bazerman propõe que o pesquisador "precisa colher informações não só sobre os textos, mas também sobre como as outras pessoas entendem esses textos" (BAZERMAN, 2005, p. 42). De acordo com Bazerman, a forma mais simples de fazer isso é pedir às pessoas envolvidas que nomeiem os gêneros com que trabalham. No questionário que embasa esta pesquisa, foi pedido aos alunos, entre outras coisas, que listassem os gêneros com que se deparam no curso, tanto do ponto de vista da escrita como da leitura.

Para a análise dos gêneros como agrupamento, adotamos os conceitos de conjunto e colônia de gêneros, conforme definidos pelos autores citados. Uma vez que, além de se concentrar nos gêneros em uso no curso de especialização, o estudo tem implicações para a compreensão de como os estudantes lidam com práticas de leitura e escrita na universidade, levamos em conta ainda o conceito de letramentos acadêmicos como proposto por Mary R. Lea e Brian V. Street (1998).

Desta forma, para o desenvolvimento do texto, primeiramente defenderemos que os gêneros podem (e em muitos casos devem) ser abordados como agrupamentos, e não como entidades estanques, apresentando os principais conceitos propostos para esse tipo de abordagem. Em seguida, nos concentraremos de modo especial nos conceitos de conjunto e colônia de gêneros, por se tratar das categorias centrais que orientam o estudo. Num terceiro momento, discutiremos a relação entre a perspectiva de gêneros em agrupamentos e os processos de letramentos acadêmicos dos alunos no contexto universitário. Finalmente, apresentaremos dados concernentes às atividades de escrita e leitura desenvolvidas pelos alunos do supramencionado curso de especialização, procurando relacioná-las com os conceitos sob análise.

\section{Da inter-relação entre os gêneros no mundo real}

Diversos autores têm chamado a atenção para a limitação metodológica de se tomar isoladamente um gênero para análise, desprezando-se as complexas inter-relações que marcam a produção, circulação e recepção dos gêneros no "mundo real", para lembrar a expressão usada por Bhatia (2004). Conforme defende John Swales (2004), a ideia é que os gêneros sejam vistos 
preferencialmente como "redes complexas de variada espécie" e não mais como "recursos comunicativos isolados e talvez separáveis". De fato, para o autor, "uma das mais importantes questôes atuais na abordagem de gêneros em Inglês para Fins de Pesquisa são as relações e ligações entre os vários gêneros" (SWALES, 2004, p. 12).

Um dos aspectos relevantes nessa abordagem é a possibilidade de considerar os gêneros inclusive na sua relação com a oralidade e a escrita. No mundo da pesquisa acadêmica, por exemplo, a origem de um artigo científico pode estar relacionada com a escrita de um resumo e com uma apresentação oral em evento científico. Inversamente, a produção de um artigo científico pode levar a uma apresentação oral na forma de conferência ou de participação em mesa-redonda.

De acordo com Bhatia (2004), hoje a teoria de gêneros textuais vem sendo desafiada pelo "mundo real do discurso" de variadas maneiras, principalmente na forma como lida com seu objeto de pesquisa, os gêneros. Interesses aplicados frequentemente fazem com que os gêneros sejam tomados como entidades estanques, dotadas de "integridade" e estabilidade, não oferecendo maiores dificuldades como objetos de investigação. Segundo Bhatia, a noção de que os gêneros são entidades passíveis de estudo como formas puras é "muito atraente e extremamente útil para uma diversidade de aplicaçóes pedagógicas; contudo, na prática, é incapaz de captar as complexas realidades comunicativas do mundo profissional e acadêmico atual" (BHATIA, 2004, p. 80).

Ainda de acordo com o autor, o mundo real nos confronta com gêneros que "frequentemente são vistos em relação com outros gêneros, com certo grau de sobreposição ou até, por vezes, de conflito" (BHATIA, 2004, p. 29), em agrupamentos ou "constelaçóes" alternativamente designados por diferentes rótulos, como veremos adiante.

Com fundamentação teórica principalmente em Bhatia (2004), a abordagem de agrupamentos de gêneros foi usada como categoria central em Benedito G. Bezerra (2006), que investigou a constituição de uma colônia de gêneros em torno do livro acadêmico, representada por gêneros como prefácio, apresentação, prólogo, introdução, nota biográfica, sinopse e até agradecimentos, dedicatória e epígrafe. Posteriormente, Bezerra (2009) defende especificamente o potencial analítico do conceito de colônia para analisar gêneros que, embora tenham propósitos comunicativos em comum, transitam entre diferentes domínios disciplinares e profissionais ou, para usar um termo de Luiz Antônio Marcuschi (2002), entre diferentes domínios discursivos. 
Apresentando os estudos retóricos de gêneros, ${ }^{3}$ Anis S. Bawarshi e Mary Jo Reiff (2010, p. 82) afirmam que, "para compreender os gêneros como ação social, precisamos atentar para as constelaçôes de gêneros que coordenam açôes sociais complexas em e entre sistemas de atividades". Na visão dos autores, os representantes dessa "escola" concordam em que os gêneros não existem isoladamente, mas em interação dinâmica com outros gêneros. Consequentemente, deveriam ser abordados preferencialmente no quadro dessa interação.

A literatura especializada acumula, hoje, uma diversidade de propostas conceituais que evidenciam a importância atribuída aos agrupamentos de gêneros, bem como o seu potencial heurístico para a continuidade das pesquisas no campo. Em um levantamento terminológico e conceitual bastante abrangente, mas não necessariamente exaustivo, Bezerra (2011) tratou de nove diferentes conceitos, propostos por diferentes autores, quais sejam: "conjuntos de gêneros" (DEVITT [1991]; BAZERMAN [2005]), "sistemas de gêneros" (BAZERMAN, 1994; 2005), "hierarquias", "cadeias" e "redes de gêneros" (SWALES, 2004), "gêneros disciplinares" e "colônias de gêneros" (BHATIA, 2004), "repertórios de gêneros" (ORLIKOWSKI; YATES, 1994) e "ecologias de gêneros" (SPINUZZI, 2004). Considerando sua centralidade neste estudo, nos dedicamos em seguida a apresentar os conceitos de conjunto e colônia de gêneros.

\section{Conjuntos e colônias de gêneros}

Conjuntos e colônias de gêneros são conceitos provenientes de diferentes abordagens teóricas. Em um artigo cujo tema central é a intertextualidade, Amy Devitt se refere ao conjunto de gêneros produzido por profissionais de contabilidade, ressaltando a inter-relação entre esses textos como uma importante chave para sua compreensão: "Eles formam uma rede complexa de interação, um conjunto estruturado de relações entre textos, de modo que cada texto deve ser entendido no contexto dos outros textos" (DEVITT, 1991, p. 336). Como descrevi em trabalho anterior, ${ }^{4}$ a pesquisadora elenca, em sua pesquisa, os treze gêneros produzidos pelos contadores no exercício de sua profissão e se refere a esses textos como um "conjunto de gêneros" que

\footnotetext{
3 Tendência conhecida também como "escola norte-americana" (BHATIA, 2004, p. 10) ou, pelo menos no Brasil, como "nova retórica" ou "sociorretórica".

${ }^{4}$ Ver Bezerra (2011), de onde retomo algumas consideraçôes sobre os conceitos em foco.
} 
interagem para realizar as atividades recorrentes naquela comunidade. De acordo com ela, "quando examinamos o conjunto de gêneros de uma comunidade, estamos examinando as situações, as atividades recorrentes e os relacionamentos da comunidade. $O$ conjunto de gêneros realiza o trabalho da comunidade" (DEVITT, 1991, p. 340).

Apropriando-se do conceito, Bazerman (2005, p. 318) define conjunto de gêneros como "a coleção de tipos de texto que alguém, em um determinado papel, provavelmente produzirá". Segundo o autor, quando catalogamos todos os gêneros que uma pessoa pode falar ou escrever, no exercício de seu papel profissional, estamos identificando boa parte do funcionamento desses gêneros. Conforme essa definição, teremos que concordar com Spinuzzi (2004) em que o conceito de conjunto de gêneros apresenta um foco no indivíduo e, assim, é capaz de oferecer um quadro apenas parcial do funcionamento dos gêneros em contextos do "mundo real". Segundo Bhatia (2004), os gêneros que formam um conjunto, embora intertextualmente ligados, se mostram "individualmente distintos" e revelam apenas um lado da atividade profissional, aspecto igualmente já destacado por Bazerman (1994).

Para dar conta de aspectos não cobertos pelo conceito de conjunto de gêneros, como gêneros que mantêm uma ligação recíproca dentro e através de diferentes domínios discursivos, Bhatia (2004) apresenta a noção de colônia de gêneros. Conforme o autor, a noção de colônia de gêneros resulta da versatilidade que permite a manifestação dos gêneros, bem como a respectiva análise, em diversos níveis de generalização. Numa mesma colônia, os gêneros, apesar de se mostrarem inter-relacionados, "não necessariamente respeitam fronteiras e domínios disciplinares" (BHATIA, 2004, p. 57).

De acordo com Bhatia, o conceito de colônia de gêneros desempenha uma dupla função dentro da teoria de gêneros: por um lado, permite um alto grau de versatilidade na identificação e descrição dos gêneros, propiciando estabelecer relações recíprocas entre esses gêneros em diferentes níveis de especificidade. Por outro lado, torna possível ainda relacionar gêneros especificamente identificados com aspectos do contexto sociocomunicativo mais amplo.

Adicionalmente, o conceito de colônia de gêneros apresenta um duplo significado, que vem reforçar seu potencial para a análise de gêneros. Primeiro, entenda-se colônia como "um agrupamento de gêneros intimamente relacionados" que em grande parte partilham propósitos comunicativos comuns, enquanto se diferenciam por aspectos como filiação disciplinar, 
contexto de uso, relacionamento entre os participantes e restrições determinadas pelo público a que se destinam, entre outros fatores. Em segundo lugar, é fundamental perceber que a noção de colônia de gêneros inclui ainda o sentido de um processo de "colonização", pelo qual acontece "a invasão da integridade de um gênero por outro gênero ou convenção genérica, levando freqüentemente à criação de formas híbridas" (BHATIA, 2004, p. 58), especialmente formas guiadas por propósitos promocionais.

Por possibilitar simultaneamente a representação de agrupamento de gêneros pertencentes a um ou mais domínios discursivos, profissionais ou acadêmicos ("membros primários" da colônia), bem como a visualização dos processos de apropriação e exploração dos recursos dos gêneros para a criação de gêneros híbridos ("membros secundários"), o conceito de colônia de gêneros se torna "crucial para o quadro teórico da análise de gêneros" (BHATIA, 2004, p. 58).

Neste artigo, como sinalizado anteriormente, refletimos sobre como ambos os conceitos acima expostos podem ser concretamente aplicados a uma determinada "constelação" de gêneros, nomeadamente, os gêneros com que se deparam os alunos no decorrer de um curso de pós-graduação lato sensu.

\section{Gêneros textuais e letramentos acadêmicos}

A expressão letramentos acadêmicos, segundo autores representativos dos assim chamados novos estudos do letramento, designa os processos pelos quais os alunos aprendem a lidar com práticas de leitura e escrita no ensino superior de graduação e pós-graduação. Presume-se que não se trata apenas de aplicar uma habilidade geral de leitura ou escrita, adquirida em níveis anteriores da educação formal, nem da simples socialização do aluno no meio acadêmico, mas de lidar com desafios novos em um contexto de aprendizagem também novo. Conforme Lea e Street, "a aprendizagem no ensino superior implica a adaptação a novas formas de saber: novas maneiras de compreender, interpretar e organizar o conhecimento" (LEA; STREET, 1998, p. 157). No dizer de Bartholomae (1985), o processo de letramento acadêmico implica "inventar a universidade" para cada ocasião, dependendo inclusive da área específica do saber em que o aluno está se inserindo:

Cada vez que se senta para escrever para nós, o aluno tem que inventar a universidade para aquela circunstância - inventar a universidade, ou seja, uma ramificação dela, como História, Economia, Antropologia 
ou Inglês. Ele tem que aprender a falar nossa linguagem, falar como falamos, experimentar formas específicas de saber, selecionar, avaliar, relatar, concluir e argumentar que definem o discurso de nossa comunidade (LEA; STREET, 1985, p. 273).

Diversos autores discutem a natureza e as peculiaridades desse processo por que todo aluno passa ao ingressar na universidade em qualquer um de seus níveis, inclusive na pós-graduação stricto sensu, a exemplo de Figueiredo e Bonini (2006), que discutem problemas na escrita de alunos de mestrado. ${ }^{5}$

Uma vez que se trata de discutir a leitura e produção de textos no âmbito da universidade, inevitavelmente surge a pergunta pela relação entre os gêneros textuais e os letramentos acadêmicos. Concretamente, o processo de inserção e aculturação do aluno no ensino superior ocorre sempre mediado por gêneros, uma vez que são eles os textos reais que organizam "atividades e pessoas" (BAZERMAN, 2005). As dificuldades encontradas por alunos na leitura el ou produção de resumos, resenhas, artigos científicos, ensaios, projetos de pesquisa, dissertaçôes e teses evidentemente são, como se vê, problemas no lidar com gêneros textuais próprios do ambiente acadêmico, cuja configuração específica varia através das fronteiras disciplinares.

Conforme Russell et al. (2009), o conceito de gêneros está implícito em seja qual for o modelo proposto para abordar a escrita dos estudantes no ensino superior. $\mathrm{O}$ que muda é a perspectiva pela qual os gêneros são conceituados em cada caso. Seguindo-se a tipologia de modelos proposta por Lea e Street (1998), no modelo das habilidades de estudo, os gêneros são considerados a partir de seus traços formais e superficiais. No modelo da socialização acadêmica, pelo contrário, ressalta-se a conceituação dos gêneros no interior de diferentes culturas e normas disciplinares, definidas a partir dos textos "escritos por acadêmicos de uma determinada comunidade disciplinar" (RUSSELL et al., 2009, p. 405). A perspectiva dos letramentos acadêmicos, por sua vez, "se alinha com uma visão de gênero como prática social, e não com o conhecimento de gêneros em termos da comunicação disciplinar em si, embora esta seja, por sua própria natureza, essencial para uma perspectiva de prática social" (RUSSELL et al., 2009, p. 405).

Assim, consideramos que a aquisição, por parte do aluno, de habilidades de leitura e escrita acadêmica, bem como sua inserção nessas práticas no

\footnotetext{
${ }^{5}$ Para uma discussão mais detalhada sobre letramentos acadêmicos, ver, entre outros, Bezerra (2010).
} 
contexto universitário, são evidenciadas concretamente pela forma bem sucedida como lidam com os gêneros textuais específicos do meio. É a maneira de lidar com esses gêneros, quer do ponto de vista da produção, quer da recepção, que caracteriza a participação mais ou menos periférica do aluno na comunidade acadêmica.

Consequentemente, na investigação reportada por este trabalho, concentramos nosso olhar de modo especial nas práticas de leitura e escrita desenvolvidas pelos alunos ao longo do curso de especialização, nos gêneros envolvidos em ambas as atividades e no modo como os alunos lidaram com esses gêneros.

\section{Leitura e escrita na pós-graduação}

Participar de um curso de pós-graduação lato sensu, como, de resto, participar de qualquer curso em nível universitário, pressupõe necessariamente o engajamento do estudante em variadas práticas e eventos de letramento (BARTON; HAMILTON, 2000). Além, obviamente, de saber ouvir o professor e os colegas, bem como se expressar oralmente diante deles no decorrer de aulas e atividades afins, o aluno é chamado de forma particular a participar de atividades que conferem visibilidade central a práticas de leitura e escrita de textos/gêneros acadêmicos. Qual é a natureza dessas práticas de leitura e escrita em um curso de especialização em língua portuguesa, cujo público abrange desde professores da educação básica com vasta experiência em sala de aula, mas que há muito não se veem como alunos, até jovens egressos dos cursos de Letras, com pouca ou nenhuma experiência de ensino?

Segundo o público pesquisado para este estudo, as atividades desenvolvidas no curso de especialização envolvem "interpretação", "releitura" e "produção" de textos. Apesar de que interpretação e releitura remetem a práticas de recepção, ou seja, de leitura, muitas atividades concretamente nomeadas se enquadram no tópico produção. Entre elas, os alunos se referem a "resumos", "sequências didáticas", "provas escritas", "redação", "exercícios", "fichamentos", "análises de livros didáticos", "projetos", "artigos científicos" e "resenhas" (ver Quadro 1, em que as atividades são designadas exatamente como nomeadas pelos alunos). 


\section{QUADRO 1}

Atividades desenvolvidas no curso de especialização

\begin{tabular}{|c|c|c|}
\hline Atividades de recepção & \multicolumn{2}{|c|}{ Atividades de produção } \\
\hline leitura & escrita & oralidade \\
\hline $\begin{array}{l}\text { interpretação de textos } \\
\text { releitura de textos }\end{array}$ & $\begin{array}{l}\text { produção textual } \\
\text { resumos } \\
\text { sequência didática } \\
\text { provas escritas } \\
\text { redação } \\
\text { exercícios escritos } \\
\text { projetos } \\
\text { análises de livros didáticos } \\
\text { artigos científicos } \\
\text { resenhas } \\
\text { fichamentos }\end{array}$ & $\begin{array}{l}\text { apresentação de trabalhos } \\
\text { discussōes em grupo } \\
\text { debates } \\
\text { seminários } \\
\text { exercícios orais }\end{array}$ \\
\hline
\end{tabular}

Fonte: elaboração própria.

Outras atividades reportadas pressupõem mais claramente o uso da oralidade, sem excluir, naturalmente, uma relação desta com a produção da escrita como apoio para o evento oral. Neste particular, são citados "exercícios orais [e escritos]", "apresentação de trabalhos", "discussōes em grupo", "debates" e "seminários". Note-se que, embora a produção de todos esses trabalhos implique a necessidade de leitura, esta não é mencionada em associação concreta com nenhum gênero de texto. A leitura, vista como premissa para muito do que se faz no curso, paradoxalmente se torna invisível quando se evocam atividades efetivamente realizadas como parte do processo de ensinoaprendizagem.

A propósito disso, cabe lembrar que, em seu estudo "meta-analítico" sobre pesquisas acerca do letramento no ensino superior, Maria de Lurdes Dionísio e Adriana Fischer (2010) igualmente constatam que no contexto acadêmico, ao contrário de outros contextos, se privilegia muito mais a escrita do que a leitura. Impõe-se, para as autoras, a conclusão de que "a literacia quando do contexto acadêmico diz sobretudo respeito a práticas de escrita e muito menos às de leitura", o que pode acabar gerando um "eventual desfasamento entre o que se lê e o que se escreve na universidade" (DIONÍSIO; FISCHER, 2010, p. 295), com consequências potencialmente graves para o engajamento dos alunos em práticas especializadas requeridas pela esfera científica.

O que se sugere não é propriamente que os alunos não sejam submetidos a atividades de leitura, mas que essas leituras são em larga medida invisibilizadas 
no processo de letramento, inclusive na prática pedagógica da avaliação, na ótica de professores e alunos. Embora uma resenha, por exemplo, não possa prescindir do envolvimento do aluno com a leitura da obra-fonte, a impressão que se tem é que a atividade que resulta nesse gênero é tratada primordialmente como atividade de produção, e assim avaliada, virtualmente se esquecendo do papel da leitura no processo.

A centralidade da leitura, no entanto, transparece em alguns comentários dos alunos sobre suas atividades no decorrer do curso. Chama-se a atenção, por exemplo, para os "numerosos" resumos e "fichamentos", vistos como formas de documentação de leituras, assim como se destaca a realização de seminários como estratégia para "socialização" de conteúdos lidos.

\section{Gêneros textuais na leitura e escrita dos alunos}

A pergunta pelas atividades desenvolvidas no curso de pós-graduação lato sensu, incluindo leitura, escrita e oralidade, antecipa em boa medida um panorama dos gêneros textuais envolvidos. Porém, ao serem questionados especificamente sobre com que gêneros textuais se depararam no curso, quer do ponto de vista da leitura quer da escrita, novos gêneros foram citados, permitindo delinear uma constelação mais ampla dos artefatos textuais que fazem parte da vida dos alunos ao cursarem especialização em língua portuguesa (Quadro 2).

$$
\text { QUADRO } 2
$$

Gêneros na leitura e escrita dos alunos

\begin{tabular}{l|l}
\hline \multicolumn{1}{c|}{ Leitura } & Escrita \\
\hline capítulos de livros & resumos \\
poemas & fichamentos \\
artigos científicos & redação \\
charges & poemas \\
letras de músicas & apresentações PowerPoint \\
reportagem jornalística & monografia \\
monografia & resenhas \\
resenhas & artigos científicos \\
resumos & \\
anotações do professor & \\
apresentações PowerPoint & \\
livros completos & \\
\hline
\end{tabular}

Fonte: elaboração própria. 
Como se vê, o quadro reitera a constatação de que as atividades de leitura, paradoxalmente menos visíveis, ultrapassam em número as atividades de escrita. Consequentemente, os estudantes lidam, para fins de leitura, com uma quantidade maior de gêneros em relação àqueles propostos para produção escrita. Retomando o estudo de Dionísio e Fischer (2010), verifica-se ainda que a maioria dos gêneros produzidos se enquadra na categoria das "ferramentas pedagógicas", ou seja, referem-se a atividades de escrita cuja finalidade se esgota no contexto da sala de aula, ao contrário dos "gêneros científicos", produzidos em escala bem menor, e cuja circulação ultrapassa os limites do ambiente de aprendizagem, sendo capazes de contribuir para a inserçāo do aluno na comunidade acadêmica profissional.

Entre esses gêneros destacam-se a resenha, o artigo científico e a monografia (neste caso, o trabalho de conclusão de curso). De todos os gêneros reportados como produzidos pelos alunos no decorrer do curso, apenas esses têm consequências, para a vida dos alunos, que ultrapassam a sala de aula.

A resenha e o artigo podem ser classificados como "gêneros científicos" por constituírem opções bem consolidadas no mundo da publicação acadêmica. Presume-se que sua leitura e produção no âmbito do curso poderá se configurar como uma etapa preparatória para a inserção do aluno no mundo real da pesquisa científica, tornando-se ele mesmo um autor e deixando de ser mero consumidor de gêneros acadêmicos.

Quanto à monografia, na qualidade de trabalho de conclusão do curso de especialização, contribuirá para que o aluno visualize e compreenda que os principais ritos de passagem no ambiente acadêmico são mediados por gêneros muito específicos e extremamente poderosos, tais como os TCCs (trabalhos de conclusão de curso de graduação), monografias (para conclusão de cursos de especialização), dissertações (para conclusão de cursos de mestrado) e teses (para conclusão de curso de doutorado).

Como discutimos em Bezerra (2010), entre as dificuldades reportadas para integralização do curso, os estudantes citam apenas questóes relacionadas com a produção escrita de gêneros acadêmicos. Uma aluna chega a afirmar textualmente: "na leitura não senti dificuldade". Quanto à escrita, as queixas se dividem entre gêneros acadêmicos produzidos no âmbito das disciplinas e a monografia de conclusão do curso. No primeiro caso, são mencionadas as dificuldades encontradas "na produção da resenha e na construção de um artigo científico", dois gêneros que fogem ao esquema habitual das "ferramentas pedagógicas" referidas por Dionísio e Fischer (2010) e se inserem entre os "gêneros científicos". No segundo caso, isto é, no que tange à produção da monografia, os estudantes mencionaram especialmente dificuldades com "a estrutura [do trabalho]" e com 
"a compreensão das normas da ABNT". Segundo informa uma aluna, o problema é que as normas da $\mathrm{ABNT}$ foram "cobradas superficialmente em algumas disciplinas" ao longo do curso. Outros estudantes assumem uma perspectiva de déficit, atribuindo suas dificuldades a falhas nos estudos de graduação.

\section{Leitura e escrita dos alunos: conjunto ou colônia de gêneros?}

Ao nos perguntarmos pelo enquadramento dos gêneros lidos e produzidos pelos alunos na categoria de conjunto ou de colônia, primeiramente devemos esclarecer que os gêneros levados em consideração não foram objeto de levantamento exaustivo por parte do pesquisador. Antes, o Quadro 2 (ver acima), base para esta análise, foi elaborado exclusivamente a partir das declaraçóes dos alunos, como tem ficado explícito por todo o estudo. Portanto, é muito provável que outro tipo de levantamento acarretasse o acréscimo ou supressão de algum dos gêneros aqui discutidos. ${ }^{6}$ Levando-se em conta, dessa forma, apenas os gêneros que os alunos declaram haver lido ou escrito ao longo do curso, e eliminando-se as sobreposições na leitura e na escrita, chegamos à constelação de gêneros apresentada no Quadro 3.

\section{QUADRO 3}

Agrupamento de gêneros lidos

e/ou produzidos pelos alunos

\begin{tabular}{l}
\hline anotaçōes do professor \\
apresentaçóes PowerPoint \\
artigos científicos \\
capítulos de livros \\
charges \\
fichamentos \\
letras de músicas \\
livros completos \\
monografias \\
poemas \\
redações \\
reportagem jornalística \\
resenhas \\
resumos
\end{tabular}

Fonte: elaboração própria.

\footnotetext{
${ }^{6}$ Para dar um exemplo relevante, um gênero central para a conclusão do curso e pré-condição para a produção da monografia é o projeto de pesquisa, que curiosamente não é listado pelos alunos.
} 
Em um primeiro momento, o resultado pode ser desnorteante, se esperamos um agrupamento de gêneros que mostre algum tipo de coerência e inter-relação evidente. Que têm em comum esses catorze gêneros aparentemente tão díspares? Como podemos observar, trata-se, para lembrar um conceito proposto por Marcuschi (2002), de gêneros que perpassam diferentes domínios discursivos: de gêneros jornalísticos (reportagem, charge) a gêneros do discurso pedagógico e gêneros acadêmicos, entre outros. Certamente, à primeira vista, podemos nos perguntar se esses artefatos textuais caracterizam o que Devitt (1991) e Bazerman (2005) chamaram de conjunto de gêneros. No entanto, parece haver alguns impedimentos.

Primeiramente, os alunos têm que lidar com gêneros não só em termos de produção, como prevê o conceito de conjunto de gêneros na célebre elaboração de Bazerman (2005, p. 32): "um conjunto de gêneros é a coleção de tipos de texto que uma pessoa num determinado papel tende a produzir", tanto falando como escrevendo. Participar de um curso de especialização, como de qualquer outro curso universitário, implica o envolvimento com gêneros tanto produtiva como receptivamente. ${ }^{7}$ Analisar apenas os gêneros produzidos pelos alunos, deixando de fora os que se destinam a atividades de leitura, seria abordar apenas uma parte da realidade dos estudantes. $O$ conjunto de gêneros produzidos pelos estudantes, no âmbito do curso, relaciona-se diretamente, e de forma complexa, com o conjunto de gêneros do professor, para que o processo de ensino-aprendizagem possa ocorrer.

Ressalte-se ainda que muitos gêneros que o professor apresenta ao aluno não são necessariamente produzidos pelo docente. Nota-se, portanto, que num determinado sistema de gêneros e sistema de atividades (BAZERMAN, 2005), a relação entre gêneros e conjuntos de gêneros pode ser bem mais complexa do que parece à primeira vista. Concluiríamos, consequentemente,

\footnotetext{
${ }^{7}$ É certo que, segundo Devitt (1991, p. 339), um contabilista tanto produz como recebe os textos que fazem parte do seu conjunto de gêneros, mas ainda assim se trata sempre do conjunto de gêneros produzidos por pessoas no papel social de contabilista. Não se incluem aí, digamos, gêneros recebidos dos clientes e que, consequentemente, o contabilista como tal não produz. Nesse sentido também deve ser entendida a definição de Swales (2004, p. 20), para quem o conjunto de gêneros é "aquela parte da rede de gêneros total com que um determinado indivíduo - ou, às vezes, mais precisamente uma classe de individuos - se envolve, quer receptiva, quer produtivamente, ou ambos, como parte de sua ocupação ou prática institucional regular" (grifos meus).
} 
que a totalidade dos gêneros com que o estudante lida em termos de leitura e produção não pode ser adequadamente descrita como um único conjunto de gêneros, nem pode ser coerentemente definida como resultante da produção individual de aluno e professor.

Então, será que os gêneros produzidos e lidos pelos alunos podem ser considerados uma colônia de gêneros (BHATIA, 2004)? Em certos aspectos, esse conceito parece mais adequado para rotular o agrupamento de gêneros com que se depara o aluno de pós-graduação do que a noção de conjunto de gêneros. Primeiramente, porque, ao contrário do conceito de conjunto de gêneros, a noção de colônia não se fixa na produção, e muito menos na produção individual. Como podemos perceber, os gêneros com que lidam os alunos do curso de especialização são produzidos por eles, pelos professores, por jornalistas, chargistas, compositores e escritores, e não obedecem à delimitação de um único domínio discursivo de origem.

De acordo com Bhatia (2004), o conceito de colônia de gêneros distingue-se de conjunto de gêneros, entre outros aspectos, exatamente por permitir englobar gêneros que não se limitam às fronteiras de uma única tradição disciplinar. Os membros de uma colônia de gêneros podem perfeitamente integrar outras colônias, assim como perpassar variados campos disciplinares. Entretanto, um requisito para que os gêneros sob análise se configurem como uma colônia seria o fato de manterem propósitos comunicativos em comum. Seria possível assumir que isso acontece neste caso? De que modo poderíamos afirmar que todos os gêneros expostos no Quadro 3 apresentam propósitos comunicativos comuns, pensando em gêneros tão díspares como poema e artigo científico? É certo que, no interior do curso, ambos os gêneros cumprem a função de possibilitar o processo de aprendizagem do aluno, mas seus propósitos comunicativos parecem ser muito diferentes. Assim, em princípio também não seria aconselhável rotular apressadamente os gêneros produzidos e lidos pelos alunos como uma colônia.

Portanto, apesar de percebemos, nos gêneros em questão, características tanto de conjunto como de colônia de gêneros, nenhum dos dois conceitos parece dar conta inteiramente da natureza do agrupamento. O principal elemento complicador foi a inclusão, na análise, dos gêneros dos quais os alunos participam como receptores ao lado daqueles dos quais são produtores. Esse olhar para os gêneros escritos e lidos pelos alunos no curso de pós-graduação lato sensu resultou numa realidade complexa que não pode ser reduzida a nenhum dos conceitos que à primeira vista poderiam descrevê-los. 
Um último aspecto a ressaltar, que corrobora a dificuldade de enquadramento dos gêneros sob análise em um conceito único, é a própria natureza "relativamente estável" do agrupamento. Embora as práticas de leitura e escrita desenvolvidas por alunos em cursos de pós-graduação possam mostrar significativas semelhanças nos diversos contextos disciplinares, havendo, portanto, certa estabilidade nessas práticas independentemente de onde e quando são observadas, por outro lado, essa estabilidade será sempre relativa. Parece evidente que não estamos falando de uma constelação de gêneros tão estável como seria, provavelmente, o conjunto de gêneros produzidos por contadores, advogados, médicos e outros profissionais. Os gêneros que podem ser objeto de leitura e produção escrita por alunos em um curso de pósgraduação lato sensu por certo se revelariam como um agrupamento bastante dinâmico se os observássemos em diferentes cursos, diferentes comunidades disciplinares, diferentes instituiçôes, enfim, em diferentes contextos sociais de uso.

\section{Considerações finais}

Em vista da discussão realizada neste artigo, constatamos que os gêneros que se oferecem para leitura e produção escrita por alunos em cursos de pósgraduação lato sensu não podem ser adequadamente descritos quer como colônia, quer como conjunto de gêneros. Independentemente da utilidade desses conceitos, o agrupamento de gêneros em questão se revela, antes, como uma rede complexa de inter-relações entre diferentes conjuntos de gêneros, provenientes de diferentes produtores além dos alunos e professores do curso.

Poderíamos falar de sistemas de gêneros no sentido de Bazerman (2005), mas ainda assim o referido agrupamento não seria adequadamente explicado. Nesse aspecto, concordamos com Swales em que o termo sistema "de certo modo sugere que temos uma compreensão sobre como tudo se encaixa em um 'sistema' maior do que realmente temos' (SWALES, 2004, p. 23).

Por outro lado, parece igualmente claro que os gêneros de que tratamos aqui participam de diferentes colônias de gêneros com diferentes filiações disciplinares ou em diferentes domínios discursivos. No entanto, não me parece possível reduzi-los a uma colônia de gêneros especificamente ligada ao curso de pós-graduação, tanto do ponto de vista dos propósitos comunicativos como de um eventual processo de "colonização" dos gêneros entre domínios disciplinares, como prevê o conceito. 
Concluímos, portanto, que estamos falando de uma rede complexa e dinâmica de relaçôes entre gêneros, em sentido próximo ao descrito por Swales (2004), que opta por este termo em vez de conjuntos de gêneros. Os gêneros com que se deparam os alunos em um curso de especialização, do ponto de vista da produção e da recepção, entram na rede inclusive sem uma predeterminação absoluta por parte dos idealizadores do curso, pois a inclusão de certos gêneros e não inclusão de outros dependerá, por exemplo, da individualidade de cada professor participante do curso.

Enfim, este estudo nos permitiu fazer algumas reflexôes sobre a funcionalidade de alguns conceitos existentes na literatura para a tarefa concreta de análise de gêneros no mundo real da atividade acadêmica. Percebemos concretamente que a aplicação de conceitos teóricos a objetos de pesquisa pode não ser uma tarefa tão simples e clara em todas as situações. Constatamos isso ao nos perguntar pela possibilidade de descrever os gêneros lidos e escritos por alunos de pós-graduação como um conjunto ou uma colônia de gêneros.

Outro aspecto importante que se buscou incluir no estudo é a relação entre a compreensão dos gêneros textuais oferecidos para leitura e produção e o processo de letramento acadêmico dos alunos. Dito de forma inversa, procuramos deixar claro que os letramentos acadêmicos se dão primordialmente por meio de gêneros textuais, e que lidar com esses gêneros implica o envolvimento com práticas e eventos de letramento potencialmente novos para os alunos. Em suma, nenhum aluno é tão bom escritor ou leitor que já possa ingressar em um curso de pós-graduação sabendo lidar adequadamente com os gêneros típicos do ambiente acadêmico. Não existe uma habilidade geral de letramento que, uma vez adquirida na educação básica, possa simplesmente ser transferida para o ensino superior.

Admitindo-se que os processos de letramentos por que passam as pessoas ao longo de suas vidas são processos eventualmente complexos, e admitindo-se ainda que os gêneros textuais constituem peças fundamentais nesses processos, entende-se por que o estudo e a compreensão dos gêneros, sem falar no seu ensino, só poderia se apresentar como uma tarefa igualmente complexa. Entender os gêneros em situaçōes reais de uso, em intrincada interrelação uns com os outros, e não tomados artificialmente como entidades estanques, representa apenas um aspecto dessa complexidade. 


\section{Referências}

BARTHOLOMAE, D. Inventing the University. In: ROSE, M. (Ed.). When a Writer Can't Write: Studies in Writer's Block and Others Composing Process Problems. New York: Guilford, 1985. p. 273-285.

BARTON, D; HAMILTON, M. Literacy practices. In: BARTON, D; HAMILTON, M.; IVANIC, R. (Ed.). Situated literacies: Reading and Writing in Context. London: Routledge, 2000. p. 7-15.

BAWARSHI, A. S.; REIFF, M. J. Genre: an Introduction to History, Theory, Research, and Pedagogy. West Lafayette: Parlor; The WAC Clearinghouse, 2010. BAZERMAN, C. Atos de fala, gêneros textuais e sistemas de atividades: como os textos organizam atividades e pessoas. In: e interação. São Paulo: Cortez, 2005. p. 19-46. . Gêneros textuais, tipificação

BAZERMAN, C. Systems of Genre and the Enactment of Social Intentions. In: FREEDMAN, A.; MEDWAY, P. (Ed.). Genre and the New Rethoric. London: Taylor \& Francis, 1994. p. 79-101.

BEZERRA, B. G. Agrupamentos de gêneros: discutindo terminologias e conceitos. In: CONGRESSO INTERNACIONAL DA ABRALIN, 7., 2011, Curitiba. Anais... Curitiba: Universidade Federal do Paraná, 2011. p. 602-610. Disponível em: <http://www.abralin.org/abralin11_cdrom> Acesso em: 18 jun. 2011.

BEZERRA, B. G. Colônia de gêneros introdutórios: o que é e como se constitui. In: DIONÍSIO, A. P.; HOFFNAGEL, J, C.; BARROS, K. S. M. (Org.). Um linguista, orientaçôes diversas. Recife: Editora Universitária da UFPE, 2009. v. 2, p. 265-281.

BEZERRA, B. G. Gêneros introdutórios em livros acadêmicos. 2006. Tese (Doutorado em Linguística) - Universidade Federal de Pernambuco, Recife, 2006.

BEZERRA, B. G. Leitura e produção de gêneros acadêmicos em cursos de especialização. In: JORNADA NACIONAL DE ESTUDOS LINGUÍSTICOS DO GELNE, 23., 2010, Teresina. Não publicado.

BHATIA, V. K. Analyzing Genre: Language Use in Professional Settings. London: Longman, 1993.

BHATIA, V. K. Worlds of Written Discourse: a Genre-Based View. London: Continuum, 2004.

DEVITT, A. Intertextuality in Tax Accounting: Generic, Referential, and Functional. In: BAZERMAN, C.; PARADIS, J. (Ed.). Textual Dynamics of the Professions: Historical and Contemporary Studies of Writing in Professional Communities. Madison: The University of Wisconsin Press, 1991. p. 336-357. 
DIONÍSIO, M. de L.; FISCHER, A. Literacia(s) no ensino superior: configurações em práticas de investigação. Actas do Congresso Ibérico "Ensino Superior em Mudança: Tensôes e Possibilidades”. Braga: CIEd, 2010. Disponível em: <http://repositorium.sdum.uminho.pt/bitstream/1822/10582/3/ Dion\%C3\%ADsio\%20\%26\%20Fischer\%202010.pdf> Acesso em: 31 ago. 2010.

FIGUEIREDO, D. de C.; BONINI, A. Práticas discursivas e ensino do texto acadêmico: concepçóes de alunos de mestrado sobre a escrita. Linguagem em (Dis)curso, Tubarão, v. 6, n. 3, p. 413-446, set.-dez. 2006.

LEA, M. R.; STREET, B. V. Student Writing in Higher Education: an Academic Literacies Approach. Studies in Higher Education, London, v. 23, n. 2, p. 157-172, jun. 1998.

MARCUSCHI, L. A. Gêneros textuais: definição e funcionalidade. In: DIONÍSIO, A. P.; MACHADO, A. R.; BEZERRA, M. A. (Org.). Gêneros textuais e ensino. Rio de Janeiro: Lucerna, 2002. p. 19-36.

ORLIKOWSKI, W. J.; YATES, J. A. Genre Repertoire: Norms and Forms for Work and Interaction. MIT Sloan School Working Paper \#3671-94, mar. 1994. Disponível em: <http://ccs.mit.edu/papers/CCSWP166.html\#genre5> Acesso em: 31 dez. 2010.

RUSSELL, D. R.; LEA, M.; PARKER, J.; STREET, B. V.; DONAHUE, T. Exploring Notions of Genre in "Academic Literacies" and "Writing across the Curriculum": Approaches across Countries and Contexts. In: BAZERMAN, C.; BONINI, A.; FIGUEIREDO, D. (Ed.). Genre in a Changing World. Fort Collins: The WAC Clearinghouse; West Lafayette: Parlor, 2009. p. 395-423.

SPINUZZI, C. Describing Assemblages: Genre Sets, Systems, Repertoires, and Ecologies. Computer Writing and Research Lab, White Paper Series, p. 1-9, 2004. SWALES, J. Research Genres: Exploration and Applications. Cambridge (MA): Cambridge University Press, 2004. 